\title{
Electrocardiographic changes during chest pain in unstable angina
}

\author{
ABDUR RAHIM, R. PARAMESWARAN, AND HARRY GOLDBERG \\ From the Cardiology Department and the WLMR Laboratories, Albert Einstein Medical Center, \\ Philadelphia, Pa., U.S.A.
}

Twelve-lead electrocardiograms were recorded during one or more episodes of spontaneous chest pain in 41 patients with unstable angina. Selective coronary angiography and left ventriculography were subsequently carried out in 40 patients. In the remaining patient, the coronary arteries were examined at necropsy. Among the 29 patients with significant coronary artery disease, electrocardiographic abnormalities occurred during chest pain in 24 (83\%). In 5 patients, the electrocardiogram remained unchanged during pain. It was notable that 2 of the 12 patients without significant coronary artery disease also developed electrocardiographic abnormalities during chest pain. Of the 24 patients with coronary artery disease in whom electrocardiographic abnormalities were noted, $S T$ segment elevation and $S T$ segment depression occurred with equal frequency (11 patients each), whereas isolated $T$ wave abnormality was noted less frequently (2 patients). No significant differences were observed in the severity or the extent of coronary artery disease in these 3 groups of patients, though ST segment elevation appeared to be more common in patients with old myocardial infarction. Though electrocardiographic changes occur in a high proportion of patients with coronary artery disease, the diagnostic value of the electrocardiogram recorded during chest pain is limited since false positives and false negatives are encountered in a substantial proportion of patients with the clinical features of unstable angina.

The widespread application of bypass graft surgery in the treatment of coronary artery disease has led to an increased interest in the clinical evaluation of patients with unstable angina. Despite a number of studies describing correlations between clinical findings and coronary anatomy, clinical and other non-invasive techniques have been shown to be poor predictors of the presence and severity of coronary artery obstruction (Friesinger and Smith, 1972). Thus, clinical and electrocardiographic findings may suggest coronary artery disease in patients with normal coronary arteries (Likoff $e t$ al., 1967; Scanlon et al., 1973). They may also fail to provide any clue as to the presence of critical obstruction of the left main coronary artery (DeMots et al., 1975). Though coronary angiography is the most specific means of evaluating coronary artery disease, the procedure is not entirely without risk. Further, the need to undertake urgent angiographic studies in a large number of patients often results in excessive demands on available facilities and personnel. A simple technique that would permit the selection of patients Received for publication 17 February 1977 for angiography and possible surgery would, therefore, be valuable. Since the principal manifestation of unstable angina is chest pain resulting from myocardial ischaemia, it is reasonable to expect that the electrocardiogram recorded during an episode of chest pain might be useful in detecting the presence, the severity, and the location of ischaemia. The study reported herein was undertaken to test the usefulness of the electrocardiogram recorded during chest pain in identifying patients at high risk.

\section{Patients and methods}

Patients admitted with a diagnosis of unstable angina who subsequently underwent coronary angiography form the material for this study. The diagnosis of unstable angina was based on the following criteria: (1) initial onset of progressive, crescendo angina in a patient previously free from such symptoms; (2) increase in the frequency, severity, and the duration of angina in a patient with known stable angina; (3) episodes of prolonged pain not related to precipitating factors such as 
anaemia or arrhythmia; and (4) persistence of angina in spite of treatment with bed rest, nitroglycerin, and propranolol.

All patients were admitted to the cardiac unit where nurses and technicians trained to record 12-lead electrocardiograms were available. At the time of admission, each patient was instructed to report episodes of praecordial pain to the nurse. Twelve-lead electrocardiograms were recorded during, or within 1 to 2 minutes of praecordial pain, before the administration of nitroglycerin or other medication. Where recurrent episodes of pain occurred, an attempt was made to record the electrocardiogram during each episode. Patients were excluded in whom serial electrocardiographic and enzyme abnormalities compatible with acute myocardial infarction occurred. Similarly, patients with severe congestive failure were also excluded.

The electrocardiogram recorded during pain was compared with a routine resting tracing recorded on the same day and analysed for changes in the rhythm, the PR interval, the QRS axis and duration, and deviations of the ST segment and $T$ waves. ST segment depression or elevation was considered present if there were downward or upward deviations of the ST segment of $1 \mathrm{~mm}$ or more. In patients with ST segment abnormality in the control tracing, a further increase in the ST segment deviation during pain was considered significant. In analysing the $\mathrm{T}$ waves, flattening or minor terminal inversion were disregarded. However, deep inversion, or a reversal of the polarity of the $T$ waves was interpreted as a significant change. When ST elevation and depression occurred in the same tracing in opposite leads, ST elevation was considered the primary change and recorded as such (Fig. 1 and 2).
Selective coronary angiography was performed using the Sones or the Judkins technique. A left ventriculogram in the right anterior oblique projection was also performed in each patient. In one patient who died while awaiting angiographic studies, necropsy findings were used in correlating the electrocardiograms with the coronary anatomy. Angiograms and ventriculograms were independently examined by two groups of observers. Significant coronary artery disease was thought to be present when there was a 75 per cent or greater reduction in the estimated cross-sectional area of one or more arteries. In the case of the left main coronary artery, a 50 per cent reduction in the cross-sectional area was considered significant. These criteria were based in part on the experimental work of May et al. (1963). In each patient, the number of coronary arteries involved, the severity of narrowing, and the presence of collateral vessels were recorded. Left ventriculograms were reviewed for the presence and location of areas of contraction abnormality.

\section{Results}

Clinical, electrocardiographic, and angiographic data were available in 41 patients. There were 17 men and 24 women, with ages ranging between 35 and 75 years. In 13 patients, there was evidence of a previous myocardial infarction. Twelve patients were receiving digitalis at the time of the study, but none showed evidence of toxicity; ST segment and $T$ wave abnormalities characteristic of digitalis were noted in 1 patient. In 20 patients, 2 or more electrocardiograms were recorded during successive episodes of chest pain.

Of the 41 patients, 29 had angiographic evidence

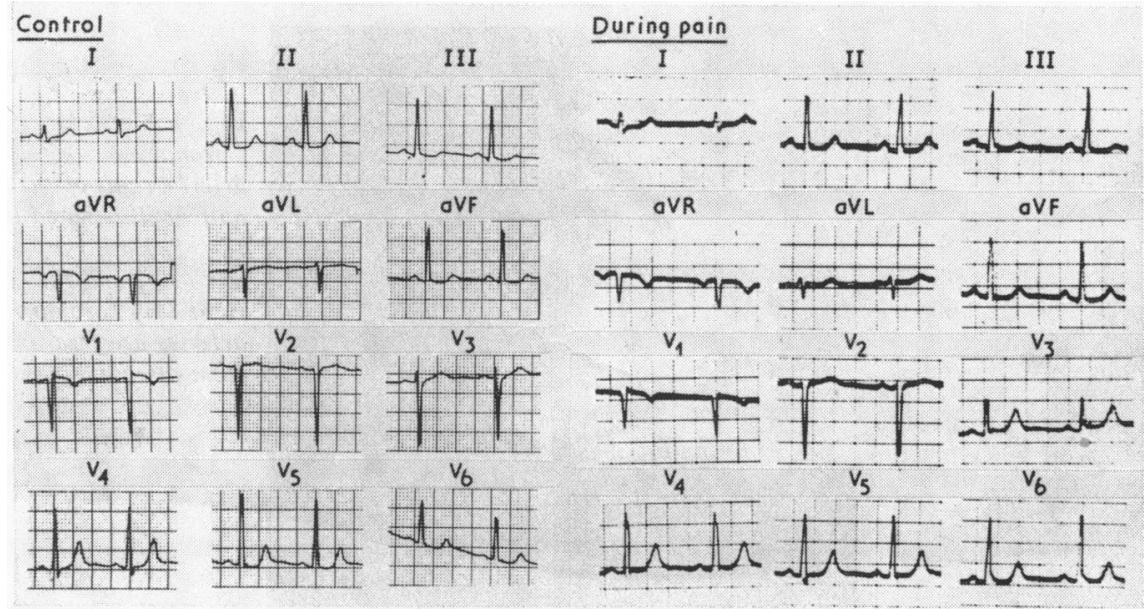

Fig. 1

Electrocardiogram recorded at rest (control), and during chest pain in a patient with normal coronary

arteries. No significant $S T$ segment and $T$ abnormalities are noted during chest pain. 


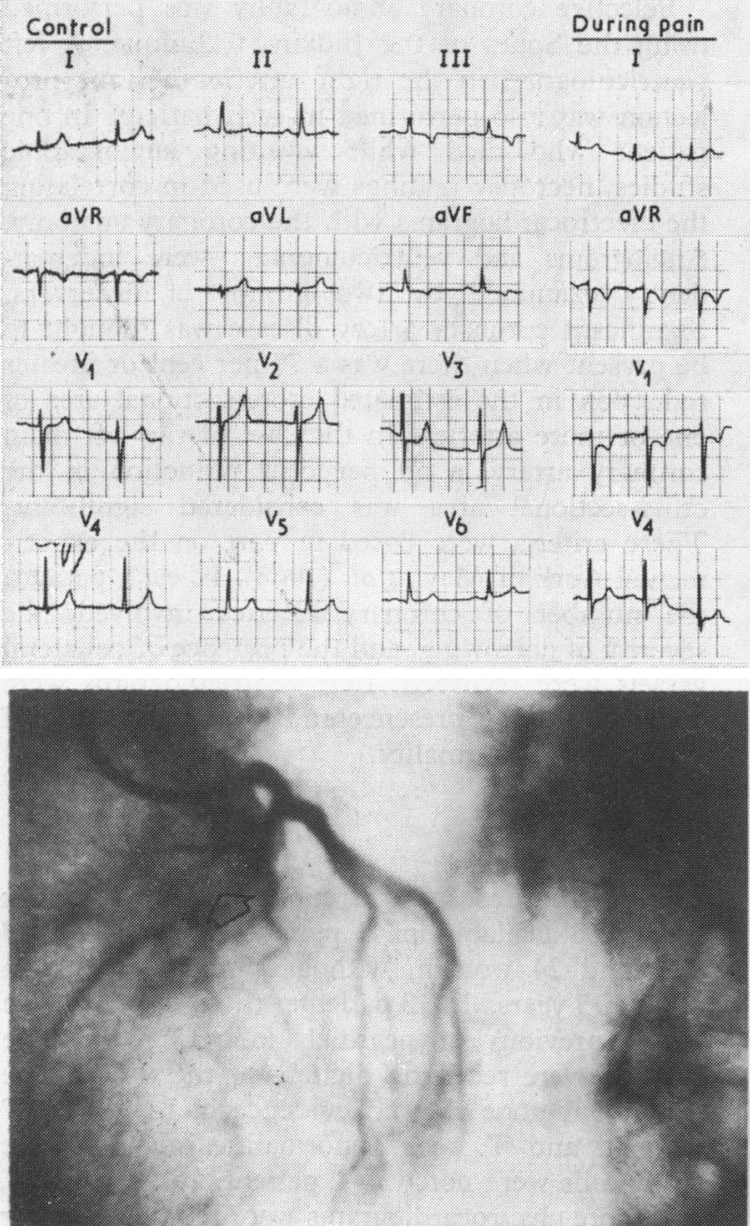

A

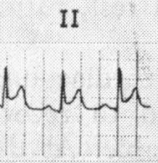

aVL.

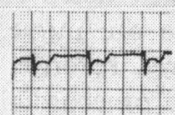

$v_{2}$

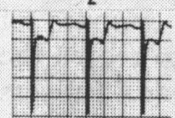

$v_{5}$

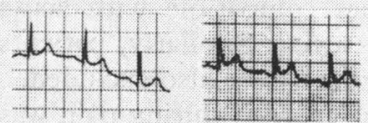

Fig. 2

Electrocardiograms recorded at rest and during chest pain in a patient with significant disease involving the right and left anterior descending coronary arteries (see Fig. 3). During pain, there is a reversal of $T$ wave polarity in leads III and $a V F$ and significant ST segment elevation in leads II, III, aVF, and V6. ST segment depression is present in leads aVL and $V 1$ to $V 3$.

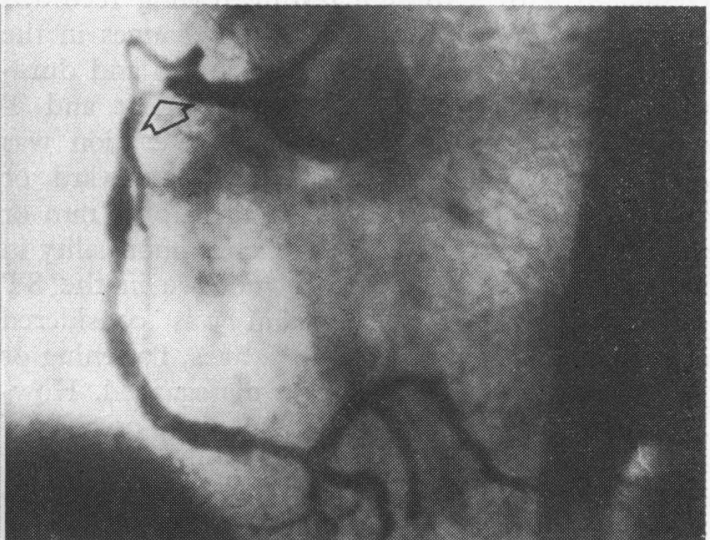

Fig. $3 \mathrm{~A}$ and B Representative frames from the coronary arteriograms of the patient illustrated in Fig. 2. Note the segmental occlusion (arrow, $A$ ) in the proximal part of the left anterior descending coronary artery. The right coronary arteriogram (B) shows discrete subtotal occlusion proximally (arrow), and diffuse disease along its entire length.

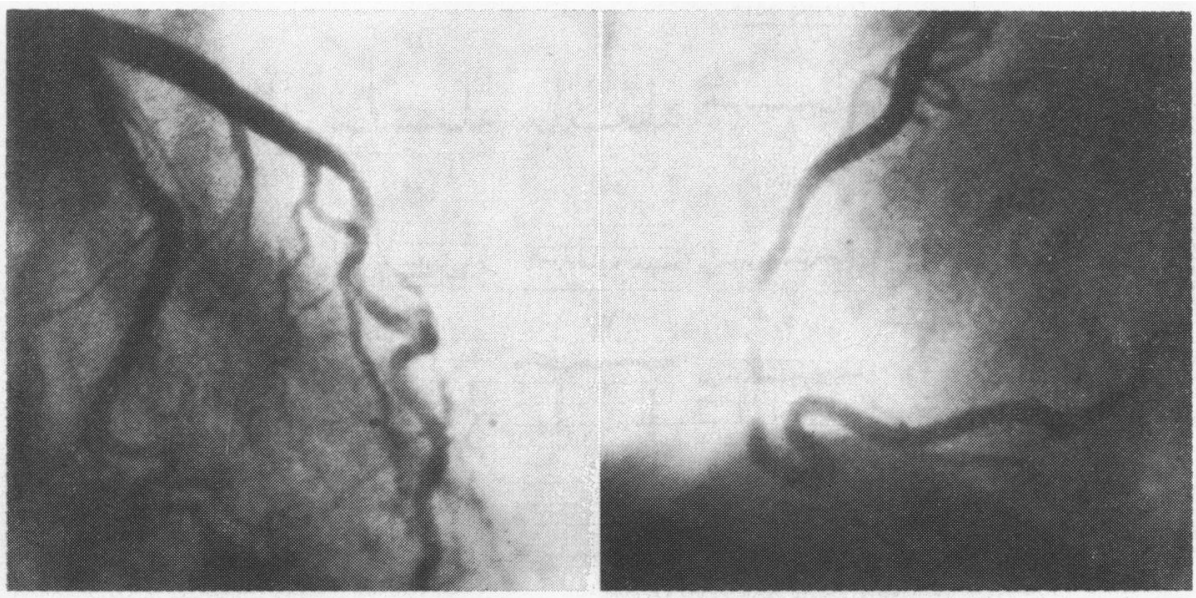

Fig. $4 \mathrm{~A}$ and $\mathrm{B}$

Coronary

arteriograms of the patient illustrated in Fig. 1. Both the left $(A)$, and the right $(B)$ coronary arteries are free from disease. 
of significant coronary artery disease (Fig. 3). Among the 12 patients without significant coronary artery disease as defined above, there were 9 patients in whom the coronary arteries were entirely normal (Fig. 4). In the remaining 3, there were luminal irregularities, or 30 to 50 per cent reduction in the estimated cross-sectional area of one or more of the coronary arteries. Details of the angiographic findings together with the other data are shown in Table 1.

With the exception of one patient in whom slight widening of the QRS complexes occurred in conjunction with ST-T abnormality during chest pain, the electrocardiographic changes during pain were confined to the ST segments and the $T$ waves. Of the 29 patients with significant coronary artery disease, 24 developed electrocardiographic abnormalities during episodes of chest pain. In 5 of these patients, these changes occurred in the face of a normal resting electrocardiogram, whereas in 19 , they were superimposed on an abnormal resting tracing. In 3 patients, the first electrocardiogram during pain indicated no significant change. However, subsequent tracings during chest pain disclosed ST segment and $T$ wave abnormality. Except for these 3 patients, the type of ST segment and $T$ wave abnormality noted during pain was similar in each patient, though there was some variability in the degree of abnormality during different episodes of pain. Of the 5 patients with coronary artery disease in whom the electrocardiogram was unchanged during pain, the disease involved a single vessel in 2 , two vessels in 1 , and three vessels in the remaining 2 patients (see Table 1). Among the 12 patients without significant coronary artery disease, the resting electrocardiogram was normal in 5, and showed ST segment and $T$ abnormality in 7 . In 10 of these 12 patients, no electrocardiographic abnormalities were observed during pain. ST segment and $T$ wave abnormalities were noted during pain in the remaining 2 patients. The coronary arteries were entirely normal in the latter 2 patients. However, both had been taking digitalis at the time of the study.

The commonest electrocardiographic abnormality during chest pain consisted of significant deviations of the ST segment, with or without concomitant T wave abnormality. Isolated $T$ wave abnormality was noted only in 2 patients. ST segment elevation and ST segment depression were noted with equal frequency in patients with coronary artery disease (11 patients each). ST segment elevation was usually confined to 2 or 3 adjacent leads, whereas ST segment depression tended to be diffuse, involving multiple leads. No significant differences were noted between these two groups of patients with respect to the severity of coronary narrowing, the number of vessels involved, or the presence of collateral vessels. There was also no significant difference in the incidence of left ventricular contraction abnormalities (Table 2). However, a greater proportion of patients with ST segment elevation had had previous myocardial infarctions. Further, in the patients with previous myocardial infarction in whom ST segment elevation occurred during pain, the abnormalities were seen to overlie the site of the old infarction.

There was no relation between the severity of coronary obstruction or the number of vessels involved, and the degree of electrocardiographic abnormality during pain. However, the location of the electrocardiographic abnormality during pain predicted the presence of significant disease in arteries known to be the major source of supply to the corresponding area of the myocardium. Thus, anterior (V1 to V4), lateral (I, aVL, V5, and V6), or anterior and lateral changes were associated with significant disease in the left anterior descending coronary artery. Similarly, inferior (II, III, aVF), or inferolateral (II, III, aVF, V5, V6) changes were noted in patients with disease in the right coronary or the circumflex coronary artery. Electrocardiographic abnormalities in the anterior, lateral, and inferior leads were associated with combined disease of the left anterior descending, right coronary, and the circumflex arteries.

\section{Discussion}

Although the electrocardiographic abnormalities during spontaneous angina are well known, there is little information concerning the frequency, or the diagnostic significance of such abnormalities in patients with unstable angina. In a group of 54 patients with preinfarction angina, Gazes et al. (1973), observed electrocardiographic changes during chest pain in $49(90 \%)$. Coronary angiography was not performed in any of the patients in this report. The need for coronary angiographic data in correlative studies of this type is apparent from the observation that a substantial number of patients with symptoms of unstable angina are free from significant coronary artery disease (Scanlon et al., 1973). In the study reported here, it was noted that electrocardiographic changes occurred in a proportion of patients $(83 \%)$ similar to that reported by Gazes et al. (1973). On the other hand, similar electrocardiographic abnormalities were noted in 2 of the 12 patients without coronary artery disease. Since the inclusion of patients with 30 to 50 per cent obstruction in the 
Table 1 Electrocardiographic and angiographic data

\begin{tabular}{|c|c|c|c|c|c|c|}
\hline \multirow{2}{*}{$\begin{array}{l}\text { Case } \\
\text { No. }\end{array}$} & \multirow{2}{*}{$\begin{array}{l}\text { Age } \\
(y)\end{array}$} & \multirow[t]{2}{*}{ Sex } & \multicolumn{2}{|l|}{ Electrocardiogram } & \multirow{2}{*}{$\begin{array}{l}\text { Coronary } \\
\text { lesions }\end{array}$} & \multirow[t]{2}{*}{ Ventriculogram } \\
\hline & & & Control & During pain & & \\
\hline 1 & 56 & $\mathbf{F}$ & Old post. infarct. T $\downarrow$ II, III, F & ST $\uparrow$ II, III, F & $\begin{array}{l}\text { RCA } \\
\text { LAD } \\
\text { CX }\end{array}$ & Diffuse hypokinesia \\
\hline 2 & 45 & $\mathbf{M}$ & $\begin{array}{l}\text { Old inf. infarct. ST and } \\
T \downarrow I I, \text { III, F }\end{array}$ & $S T \downarrow I, V 5, V 6$ & $\begin{array}{l}\text { RCA } \\
\text { Marginal }\end{array}$ & Hypokinesia, inf. wall and apex \\
\hline 3 & 48 & $\mathbf{F}$ & $\begin{array}{l}\text { Old subendo. infarct. } T \downarrow I, L \text {, } \\
\text { V1 to V3 }\end{array}$ & No change & LAD & Normal \\
\hline 4 & 52 & $\mathbf{F}$ & $\begin{array}{l}\text { Old ant. sep. infarct. } \\
\mathrm{T} \uparrow \downarrow \text { V1 to V3 }\end{array}$ & No change & $\begin{array}{l}\text { LAD } \\
\text { RCA }\end{array}$ & Dyskinesia, apex \\
\hline $\begin{array}{l}5 \\
6\end{array}$ & $\begin{array}{l}35 \\
65\end{array}$ & $\begin{array}{l}\mathbf{M} \\
\mathbf{M}\end{array}$ & $\begin{array}{l}\text { Normal } \\
\text { Old ant. sep. infarct. } \\
\text { ST and T } \downarrow \text { II, III, F, V5, V6 }\end{array}$ & $\begin{array}{l}\text { ST } \uparrow \text { V1 to V4 } \\
\text { ST } \uparrow \text { V4 to V6 }\end{array}$ & $\begin{array}{l}\text { LAD } \\
\text { LAD } \\
\text { Marginal }\end{array}$ & $\begin{array}{l}\text { Normal } \\
\text { Hypokinesia, ant. wall }\end{array}$ \\
\hline 7 & 47 & $\mathbf{M}$ & $\mathrm{T} \downarrow$ II, III, $\mathrm{F}$ & 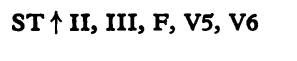 & $\begin{array}{l}\text { RCA } \\
\text { LAD }\end{array}$ & Normal \\
\hline $\begin{array}{l}8 \\
9\end{array}$ & $\begin{array}{l}52 \\
63\end{array}$ & $\begin{array}{l}\mathbf{F} \\
\mathbf{F}\end{array}$ & $\begin{array}{l}T \downarrow V 1 \text { to V3 } \\
\text { Old ant. sep. infarct. } \\
T \downarrow V 1 \text { to V3 }\end{array}$ & $\begin{array}{l}\text { No change } \\
\text { ST } \uparrow 1 \text { to V3 } \\
T \uparrow V 1 \text { to V3 }\end{array}$ & $\begin{array}{l}\text { None } \\
\text { RCA (graft) } \\
\text { LAD (graft) }\end{array}$ & $\begin{array}{l}\text { Normal } \\
\text { Diffuse hypokinesia }\end{array}$ \\
\hline 10 & 52 & $\mathbf{F}$ & Minimal ST $\downarrow$ I, L, V4 to V6 & ST $\downarrow I, L, V 4$ to V6 & $\begin{array}{l}\text { RCA } \\
\text { LAD }\end{array}$ & Diffuse hypokinesia \\
\hline $\begin{array}{l}11 \\
12\end{array}$ & $\begin{array}{l}60 \\
55\end{array}$ & $\begin{array}{l}\mathbf{M} \\
\mathbf{M}\end{array}$ & $\begin{array}{l}T \downarrow I, L, V 1, V 2 \\
\text { Old inf. post. infarct. } \\
T \uparrow \downarrow I, L, V 1 \text { to V6 }\end{array}$ & $\begin{array}{l}\text { ST } \uparrow \text { V1 to V4 } \\
\text { ST } \downarrow I, L, V 1 \text { to V6 }\end{array}$ & $\begin{array}{l}\text { LAD } \\
\text { Left main }\end{array}$ & $\begin{array}{l}\text { Normal } \\
\text { Hypokinesia, anterior wall }\end{array}$ \\
\hline 13 & 54 & $\mathbf{M}$ & ST $\downarrow$ V4 to V6 & ST $\downarrow$ II, III, F, V3 to V6 & $\begin{array}{l}\text { RCA } \\
\text { LAD } \\
\text { CX }\end{array}$ & Dyskinesia, apex \\
\hline 14 & 42 & $\mathbf{F}$ & Normal & $\mathbf{S T} \uparrow \mathbf{L}$ & $\begin{array}{l}\text { RCA } \\
\text { LAD }\end{array}$ & Normal \\
\hline 15 & 57 & $\mathbf{M}$ & $\mathbf{T} \downarrow$ II, III, F & $\begin{array}{l}\mathrm{ST} \downarrow \mathrm{V} 3 \text { to V6 } \\
\mathrm{T} \downarrow \mathrm{I}, \mathrm{L}, \mathrm{V} 1 \text { to V6 }\end{array}$ & LAD & Hypokinesia, anterial wall \\
\hline $\begin{array}{l}16 \\
17\end{array}$ & $\begin{array}{l}62 \\
62\end{array}$ & $\begin{array}{l}\mathbf{M} \\
\mathbf{F}\end{array}$ & $\begin{array}{l}\text { Normal } \\
\text { Old subendo. infarct. } \\
\text { T } \downarrow \text { II, III, F, V3 to V6 }\end{array}$ & $\begin{array}{l}\text { No change } \\
\text { ST } \uparrow \text { II, III, F }\end{array}$ & $\begin{array}{l}\text { CX } \\
\text { RCA } \\
\text { CX }\end{array}$ & $\begin{array}{l}\text { Normal } \\
\text { Normal }\end{array}$ \\
\hline 18 & 53 & $\mathbf{F}$ & Normal & $\begin{array}{l}S T \downarrow V 2 \text { to } V 6 \\
T \downarrow V 1 \text { to V6 }\end{array}$ & $\begin{array}{l}\text { RCA } \\
\text { LAD }\end{array}$ & Normal \\
\hline 19 & 52 & $\mathbf{M}$ & Normal & $\begin{array}{l}S T \downarrow I, L, V 1 \text { to V6 } \\
T \downarrow I, L, V 1 \text { to V6 }\end{array}$ & LAD & None* \\
\hline 20 & 50 & $\mathbf{F}$ & $\mathrm{T} \uparrow \downarrow \mathrm{V} 1$ to $\mathrm{V} 3$ & $\mathrm{~T} \downarrow \mathrm{I}, \overrightarrow{\mathrm{L}}, \mathrm{V} 1$ to $\mathrm{V} 4$ & $\begin{array}{l}\text { RCA } \\
\text { CX } \\
\text { LAD }\end{array}$ & Hypokinesia, anterior wall \\
\hline 21 & 58 & $\mathbf{M}$ & $\begin{array}{l}\text { Old inf. infarct. } \\
T \downarrow \text { II, III, F }\end{array}$ & $\begin{array}{l}\text { ST } \uparrow \text { III, F } \\
\mathrm{T} \uparrow \mathrm{II}, \mathrm{III}, \mathrm{F}\end{array}$ & $\begin{array}{l}\text { RCA } \\
\text { LAD } \\
\text { CX }\end{array}$ & Dyskinesia, inferior wall \\
\hline 22 & 75 & $\mathbf{F}$ & $\begin{array}{l}\text { Old inf. infarct. } \\
\mathrm{T} \downarrow \mathrm{I}, \mathrm{L}, \mathrm{V} 4 \text { to } \mathrm{V} 6\end{array}$ & $\mathrm{ST} \downarrow \mathrm{I}, \mathrm{L}, \mathrm{V4}$ to $\mathrm{V} 6$ & $\begin{array}{l}\text { RCA } \\
\text { CX } \\
\text { LAD }\end{array}$ & $\begin{array}{l}\text { Dyskinesia, } \\
\text { inferior wall and apex }\end{array}$ \\
\hline 23 & 65 & $\mathbf{M}$ & Normal & $\begin{array}{l}\text { ST } \downarrow \text { V4 to V6 } \\
\text { T } \downarrow \text { II, III, F }\end{array}$ & $\begin{array}{l}\text { RCA } \\
\text { CX } \\
\text { LAD }\end{array}$ & Normal \\
\hline 24 & 49 & $\mathbf{F}$ & Normal & No change & $\begin{array}{l}\text { RCA } \\
\text { LAD } \\
\text { CX }\end{array}$ & Normal \\
\hline $\begin{array}{l}25 \\
26 \\
27 \\
28\end{array}$ & $\begin{array}{l}33 \\
43 \\
42 \\
56\end{array}$ & $\begin{array}{l}\mathbf{M} \\
\mathbf{F} \\
\mathbf{M} \\
\mathbf{M}\end{array}$ & $\begin{array}{l}\text { Normal } \\
\text { T } \uparrow \downarrow \text { II, III, F } \\
\text { Diffuse ST sagging } \\
\text { Old ant. infarct. } \\
\text { ST } \downarrow \text { II, III, F }\end{array}$ & $\begin{array}{l}\text { No change } \\
\text { No change } \\
\text { No change } \\
\text { ST } \uparrow \text { V2 to V4 }\end{array}$ & $\begin{array}{l}\text { None } \\
\text { None } \\
\text { None } \\
\text { RCA } \\
\text { CX } \\
\text { LAD }\end{array}$ & $\begin{array}{l}\text { Normal } \\
\text { Normal } \\
\text { Normal } \\
\text { Aneurysm, apex }\end{array}$ \\
\hline $\begin{array}{l}29 \\
30 \\
31 \\
32 \\
33\end{array}$ & $\begin{array}{l}63 \\
48 \\
35 \\
42 \\
51\end{array}$ & $\begin{array}{l}\mathbf{F} \\
\mathbf{F} \\
\mathbf{F} \\
\mathbf{M}\end{array}$ & $\begin{array}{l}\text { T } \downarrow \text { V2 to V6 } \\
\text { Normal } \\
\text { T } \downarrow \text { II, III, F, V5, V6 } \\
\text { T II, III, F } \\
\text { Old inf. infarct. } \\
\text { T } \downarrow I, L, \text { V3 to V6 }\end{array}$ & $\begin{array}{l}\text { No change } \\
\text { No change } \\
\text { No change } \\
\text { No change } \\
\text { ST } \uparrow \text { V2 to V5 }\end{array}$ & $\begin{array}{l}\text { None } \\
\text { None } \\
\text { None } \\
\text { None } \\
\text { RCA } \\
\text { LAD } \\
\text { CX }\end{array}$ & $\begin{array}{l}\text { Normal } \\
\text { Normal } \\
\text { Normal } \\
\text { Normal } \\
\text { Aneurysm, anterior wall }\end{array}$ \\
\hline $\begin{array}{l}34 \\
35 \\
36 \\
37 \\
38\end{array}$ & $\begin{array}{l}63 \\
72 \\
58 \\
64 \\
54\end{array}$ & $\begin{array}{l}\mathbf{F} \\
\mathbf{F} \\
\mathbf{F} \\
\mathbf{M}\end{array}$ & $\begin{array}{l}\text { T } \downarrow \text { II, III, F, V4 to V6 } \\
\text { ST } \downarrow \text { V4 to V6, T } \downarrow \text { V4 to V6 } \\
\text { ST } \downarrow \text { I, II, L, V4 to V6 } \\
\text { T } \downarrow \text { II, III, F, V4 to V6 } \\
\text { T } \downarrow \text { II, III, F, V4 to V6 }\end{array}$ & $\begin{array}{l}\text { T } \uparrow \text { II, III, F } \\
\text { No change } \\
\text { ST } \downarrow \text { I, II, I, V2 to V6 } \\
\text { ST II, II, V2 to V6 } \\
\text { ST } \downarrow I, I I, L, V 2 \text { to V6 }\end{array}$ & $\begin{array}{l}\text { RCA } \\
\text { None } \\
\text { None } \\
\text { RCA } \\
\text { Left main } \\
\text { RCA } \\
\text { CX }\end{array}$ & $\begin{array}{l}\text { Hypokinesia, inferior wall } \\
\text { Normal } \\
\text { Normal } \\
\text { Normal } \\
\text { Normal }\end{array}$ \\
\hline
\end{tabular}


Table 1 Continued

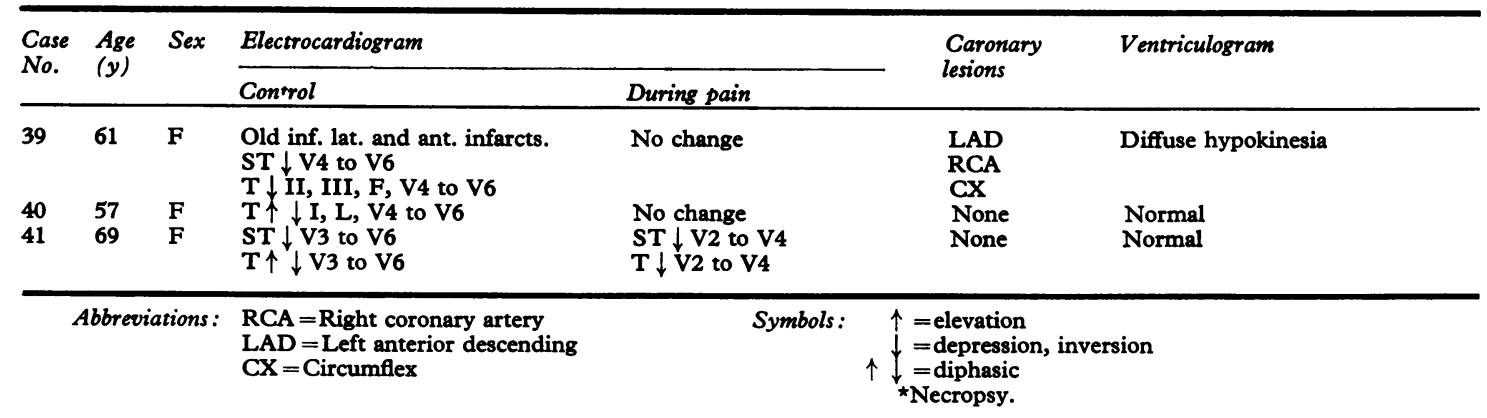

Table 2 Relation of ST segment abnormality to angiographic findings*

\begin{tabular}{|c|c|c|c|c|c|c|c|c|}
\hline \multirow[t]{2}{*}{ Electrocardiogram } & \multicolumn{5}{|c|}{ No. of vessels involved } & \multirow{2}{*}{$\begin{array}{l}\text { Abnormal } \\
\text { ventriculogram }\end{array}$} & \multirow{2}{*}{$\begin{array}{l}\text { Collateral } \\
\text { vessels }\end{array}$} & \multirow{2}{*}{$\begin{array}{l}\text { Old } \\
\text { infarction }\end{array}$} \\
\hline & None & Single & Double & Triple & L. main & & & \\
\hline $\begin{array}{l}\text { ST elevation } \\
\text { ST depression } \\
\text { No ST deviation }\end{array}$ & $\begin{array}{r}0 \\
2 \\
10\end{array}$ & $\begin{array}{l}1 \\
1 \\
2\end{array}$ & $\begin{array}{l}5 \\
5 \\
1\end{array}$ & $\begin{array}{l}5 \\
3 \\
2\end{array}$ & $\begin{array}{l}0 \\
2 \\
0\end{array}$ & $\begin{array}{l}6 \\
6 \\
2\end{array}$ & $\begin{array}{l}5 \\
6 \\
1\end{array}$ & $\begin{array}{l}6 \\
3 \\
3\end{array}$ \\
\hline
\end{tabular}

^In 39 patients (excluding 2 with isolated $\mathrm{T}$ wave abnormality).

group without coronary artery disease may be considered arbitrary, it should be emphasised that the coronary arteries were entirely normal in the 2 patients in whom electrocardiographic changes were noted during pain. The absence of electrocardiographic abnormalities during pain in 5 patients with coronary artery disease, and their development in 2 patients with normal coronary arteries suggests that the value of electrocardiography during pain in separating patients with coronary artery disease from those without is severely limited. The reasons underlying the absence of electrocardiographic abnormalities in the 5 patients with coronary artery disease are unclear. One might speculate that ischaemia might not have been sufficiently severe or prolonged to give rise to electrocardiographic abnormality, or that ischaemia may have occurred in areas of the myocardium that are electrically silent. A similar uncertainty exists regarding the development of electrocardiographic abnormality during chest pain in the 2 patients with normal coronary arteries. Such changes during exercise have in the past been attributed to digitalis therapy, or vasoregulatory abnormalities (Friesinger et al., 1972). The spontaneous occurrence of coronary artery spasm has been well documented (Chahine and Luchi, 1976) and is an additional possibility to be considered. Though spasm was not shown during angiography in any of the patients in this study, the possibility that it might have occurred at other times cannot be entirely ruled out since it has been suggested that the tendency to develop spasm may be masked by the routine administration of vasodilators during coronary angiography (Chahine et al., 1975).

Neither the degree of ST segment and T wave abnormality, nor its extent seemed to have any relation to the severity of coronary artery disease. However, a relation was noted between the location of the electrocardiographic abnormalities and the site of the disease in the coronary arteries. Thus, electrocardiographic abnormalities in the anterior and the lateral leads were associated with disease in the left anterior descending and the marginal arteries. Similarly, changes in the inferior and the inferolateral leads occurred in patients with right coronary and circumflex disease. Though ST segment and $T$ wave changes were indicative of disease in the arteries supplying corresponding areas of the myocardium, significant additional disease involving other vessels was also noted. This was particularly common in the case of the right coronary artery (Table 1). Whether this was the result of a relative insensitivity of the electrocardiographic leads to the occurrence of ischaemia in the inferior wall could not be determined.

Since its recognition as a cardinal feature of the variant form of angina pectoris, there has been considerable interest in the occurrence of ST 
segment elevation during angina. Early clinical studies (Prinzmetal et al., 1959) suggested that this phenomenon was the result of severe ischaemia resulting from critical stenosis of a large coronary artery. It has subsequently been shown that ST segment elevation during chest pain may occur in association with a variety of arteriographic patterns (Silverman and Flamm, 1971; MacAlpin et al., 1973; Oliva et al., 1973). Plotnick and Conti (1975), in a recent study, concluded that ST segment elevation during pain had no predictive value with respect to the angiographic anatomy, or left ventricular dynamics. The results in this present study confirm and extend the observations made by Plotnick and Conti. Thus, ST segment elevation was observed frequently in patients with unstable angina. Further, there were no significant differences between patients with the two types of ST segment abnormality during chest pain with respect to the severity of coronary disease, or the presence of left ventricular contraction abnormalities. In contrast to the findings of Plotnick and Conti, however, there was a preponderance of patients with old myocardial infarction in the group showing ST segment elevation. It is notable that a similar ST segment elevation has been observed in leads overlying an old myocardial infarction during exercise tests (Kattus, 1974). Experimental studies by Ekmekci et al. (1961) have suggested that in comparison with ST segment depression, ST segment elevation signifies more severe ischaemia. Whether the presence of an old myocardial infarction predisposes to, or simply reflects more severe ischaemia in patients with ST segment elevation as observed in this study is not clear.

\section{References}

Chahine, R. A., and Luchi, R. J. (1976). Coronary arterial spasm: culprit or bystander? American fournal of Cardiology, 37, 936-937.

Chahine, R. A., Raizner, A. E., Ishimori, T., Luchi, R. J., and McIntosh, H. D. (1975). The incidence and clinical implications of coronary artery spasm. Circulation, 52, 972978.

DeMots, H., Bonchek, L. I., Rösch, J., Anderson, R. P., Starr, A., and Rahimtoola, S. H. (1975). Left main coronary artery disease. Risks of angiography, importance of co- existing disease of other coronary arteries, and effects of revascularization. American fournal of Cardiology, 36, 136141.

Ekmekci, A., Toyoshima, H., Kwoczynski, J. K., Nagaya, T., and Prinzmetal, M. (1961). Angina pectoris. IV. Clinical and experimental difference between ischemia with ST elevation and ischemia with ST depression. American Fournal of Cardiology, 7, 412-426.

Friesinger, G., Biern, R. O., Likar, I., and Mason, R. E. (1972). Exercise electrocardiography and vasoregulatory abnormalities. American fournal of Cardiology, 30, 733740.

Friesinger, G., and Smith, R. (1972). Correlation of electrocardiographic studies and arteriographic findings with angina pectoris. Circulation, 46, 1173-1184.

Gazes, P. C., Mobley, E. M., Faris, H. M., Duncan, R.C., and Humphries, G. B. (1973). Pre-infarctional (unstable) angina-a prospective study-ten-year follow-up. Prognostic significance of electrocardiographic changes. Circulation, 48, 331-337.

Kattus, A. A. (1974). Exercise electrocardiography: recognition of the ischemic response, false positive and false negative patterns. American fournal of Cardiology, 33, 721731.

Likoff, W., Segal, B., and Kasparian, H. (1967). Paradox of normal selective coronary arteriograms in patients considered to have unmistakable coronary heart disease. New England fournal of Medicine, 276, 1063-1066.

MacAlpin, R. N., Kattus, A. A., and Alvaro, A. B. (1973). Angina pectoris at rest with preservation of exercise capacity. Prinzmetal's variant angina. Circulation, 47, 946958.

May, A. G., DeWeese, J. A., and Rob, C. G. (1963). Hemodynamic effects of arterial stenosis. Surgery, 53, 513-524.

Oliva, P. B., Potts, D. E., and Pluss, R. G. (1973). Coronary artery spasm in Prinzmetal angina. Documentation by coronary arteriography. New England fournal of Medicine, 288, 745-751.

Plotnick, G. D., and Conti, C. R. (1975). Transient ST segment elevation in unstable angina. Clinical and hemodynamic significance. Circulation, 51, 1015-1019.

Prinzmetal, M., Kennamer, R., Merliss, R., Wada, T., and Bor, N. (1959). Angina pectoris. I. A variant form of angina pectoris. American fournal of Medicine, 27, 375388.

Scanlon, P. J., Nemickas, R., Moran, J. F., Talano, J. V., Amirparviz, F., and Pifarre, R. (1973). Accelerated angina pectoris. Clinical, hemodynamic, arteriographic, and therapeutic experience in 85 patients. Circulation, 47, 1926.

Silverman, M. E., and Flamm, M. D. (1971). Variant angina pectoris. Anatomic findings and prognostic implications. Annals of Internal Medicine, 75, 339-343.

Requests for reprints to Dr. R. Parameswaran, Cardiology Department, Albert Einstein Medical Center, York and Tabor Roads, Philadelphia, Pennsylvania 19141, U.S.A. 